\title{
RESISTOR-NETWORK FORMULATION OF FORCED CONVECTION IN ASYMMETRICALLY-HEATED CHANNELS - HYDRODYNAMICALLY-DEVELOPED LAMINAR FLOW
}

David Naylor

Professor

Department of Mechanical \& Industrial Engineering

Ryerson University

Toronto, ON, M5B 2K3, Canada

Seyed Sepehr Mohaddes Foroushani

PhD Candidate

Department of Mechanical \& Mechatronics Engineering

University of Waterloo

Waterloo, ON, N2L 3G1, Canada

John L. Wright

Professor

Department of Mechanical \& Mechatronics Engineering

University of Waterloo

Waterloo, ON, N2L 3G1, Canada

December 2015 


\section{SUMMARY}

The computation of forced-convective heat transfer from the walls of an asymmetrically heated channel to the fluid passing through in a laminar, hydrodynamically-developed flow is known as the asymmetric Graetz problem. Several analytical and numerical solutions for this problem have been published and many variations and extensions have been investigated. Recently, there has been a renewed interest in this problem due to its applications in emerging areas such as microchannels and fuel cells. In the present work, the asymmetric Graetz problem is examined in a resistor-network framework. The formulation of the problem in terms of three convective resistances leads to temperature-independent Nusselt numbers that are free of the singularities

found in previous results. The proposed approach also offers more detail regarding the split of heat transfer between the channel walls and the flow. This work is part of an ongoing project on resistor-network modeling and characterization of multi-temperature convection problems. 


\section{ACKNOWLEDGEMENTS}

The authors gratefully acknowledge the financial support of the Smart Net-Zero Energy

Buildings Strategic Research Network (SNEBRN) of the Natural Sciences and Engineering Research Council of Canada (NSERC) and the University of Waterloo. 


\section{NOMENCLATURE}

$\mathrm{C}_{\mathrm{n}} \quad$ series solution coefficient [-]

$\mathrm{C}_{\mathrm{p}} \quad$ specific heat at constant pressure $[\mathrm{J} / \mathrm{kgK}]$

$f_{n} \quad$ eigenfunction [-]

$\mathrm{H} \quad$ channel spacing [m]

$\mathrm{k}$ thermal conductivity [W/mK]

$\mathrm{Nu} \quad$ local Nusselt number [-]

$\overline{\mathrm{Nu}} \quad$ average Nusselt number [-]

Pr Prandtl number [-]

q heat flux [W/m2]

$\mathrm{Q} \quad$ heat transfer rate (per unit width) $[\mathrm{W} / \mathrm{m}]$

$\mathrm{r}_{\mathrm{T}} \quad$ temperature ratio (Eq. 1) [-]

$\mathrm{R}$ (unit-width) thermal resistance $[\mathrm{mK} / \mathrm{W}]$

Re Reynolds number (Eq. 3) [-]

$\mathrm{T} \quad$ Temperature [K]

$\mathrm{x}$ flow-wise coordinate from inlet [m]

$\mathrm{X} \quad$ inverse Graetz number (Eq. 3) [-]

y coordinate perpendicular to walls [m]

$\bar{y} \quad$ dimensionless y-coordinate [-]

\section{Greek Symbols}

$\theta \quad$ dimensionless temperature [-]

$\lambda_{n} \quad$ eigenvalue [-]

dynamic viscosity $[\mathrm{kg} / \mathrm{ms}]$

$\rho \quad$ density $\left[\mathrm{kg} / \mathrm{m}^{3}\right]$

\section{Subscripts}

0 fluid at the inlet

1 upper wall

2 lower wall

$\mathrm{i}$ at node $\mathrm{i}$

ij paired: from node $\mathrm{i}$ to node $\mathrm{j}$

$\mathrm{m}$ bulk (mean) value

wm wall mean 


\section{INTRODUCTION}

A laminar, hydrodynamically-developed flow at temperature $\mathrm{T}_{0}$ enters the channel formed between two semi-infinite parallel plates maintained at temperatures $T_{1}$ and $T_{2}$. The plates are spaced at distance H. See Figure 1. The fluid properties $\left(k, \rho, \quad, C_{p}\right)$ are assumed to be constant. The problem of computing the heat transfer between the channel walls and the fluid is known as the asymmetric Graetz problem.

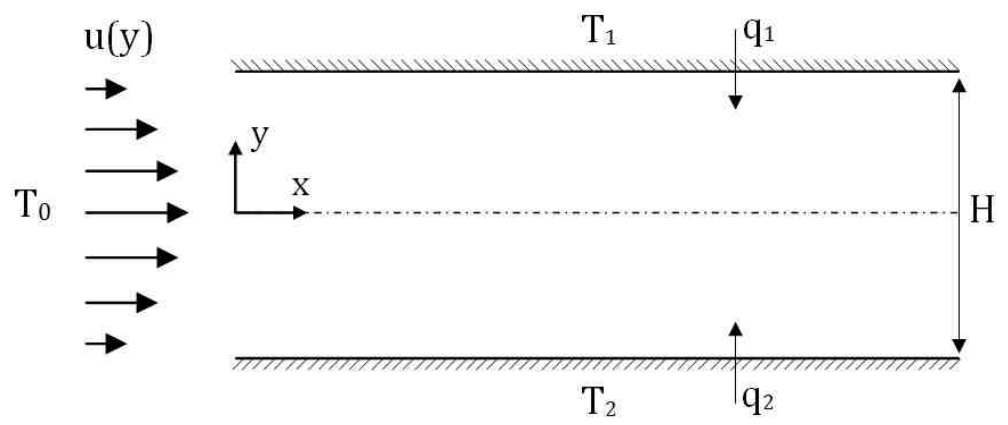

Figure 1 - Schematic of hydrodynamically developed flow in an asymmetrically heated channel

Since this is a three-temperature problem, not the customary two-temperature arrangement, it is convenient to define a temperature ratio; a constant, $\mathrm{r}_{\mathrm{T}}$, to specify the ordering of $\mathrm{T}_{0}, \mathrm{~T}_{1}$ and $\mathrm{T}_{2}-$ particularly the placement of $\mathrm{T}_{0}$ relative to $\mathrm{T}_{1}$ and $\mathrm{T}_{2}$. Equation 1 shows a common definition.

$$
\mathrm{r}_{\mathrm{T}}=\frac{\mathrm{T}_{0}-\mathrm{T}_{\mathrm{wm}}}{\mathrm{T}_{1}-\mathrm{T}_{\mathrm{wm}}}
$$

In Equation 1, $\mathrm{T}_{\mathrm{wm}}$ is the wall-mean temperature, a constant: $\mathrm{T}_{\mathrm{wm}}=\frac{\mathrm{T}_{1}+\mathrm{T}_{2}}{2}$.

It is helpful to visualize the evolution of the temperature profile and bulk fluid temperature, $\mathrm{T}_{\mathrm{m}}$, along the channel. See Figure 2, for example. At the entrance the fluid temperature is uniform: $\mathrm{T}(\mathrm{x}=0)=\mathrm{T}_{0}$. Moving downstream, due to heat transfer from the walls the temperature profile evolves approaching a linear profile at $x \rightarrow \infty$. The variation of heat flux, $\mathrm{q}_{1}$ and $\mathrm{q}_{2}$, can be judged by examining the temperature gradient, $\frac{\partial T}{\partial y}$, at the walls. In the thermally fully developed limit; (a) the temperature profile becomes linear with $\lim _{x \rightarrow \infty} \frac{\partial T}{\partial y}=\frac{T_{1}-T_{2}}{H}$, (b) $\lim _{x \rightarrow \infty} T_{m}=T_{w m}$, and (c) the 
net heat flux to the fluid decays to zero, i.e., $\lim _{x \rightarrow \infty}\left(q_{1}+q_{2}\right)=0$ because $\lim _{x \rightarrow \infty}\left(q_{1}\right)=\lim _{x \rightarrow \infty}\left(-q_{2}\right)=\frac{k}{H}\left(T_{1}-T_{2}\right)$. Attention is usually focussed on the thermal entry length because this is where the temperature profile is developing; where the net heat transfer to the fluid takes place.

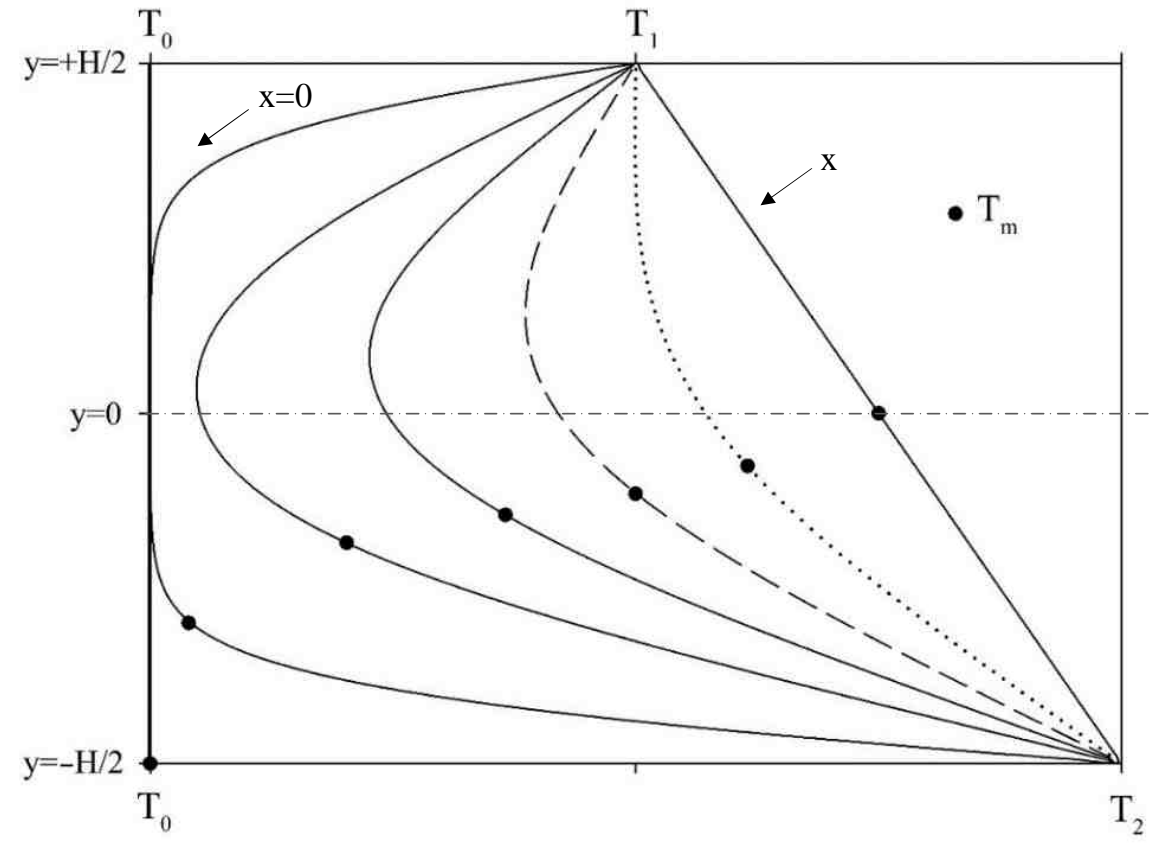

Figure 2 - Evolution of temperature profile and bulk fluid temperature $\left(\mathrm{T}_{\mathrm{m}}\right)$ in an infinitely long channel $\left(\mathrm{r}_{\mathrm{T}}=3\right)$

Heat transfer in asymmetrically heated channels has been extensively investigated. Many variations and extensions have been studied and several solutions, some analytical and some numerical, have been published. In recent years, the asymmetric Graetz problem has seen a renewed interest from researchers in emerging areas such as microchannels and fuel cells. The analytical solution by Hatton and Turton [1] is of particular interest to the present work.

With constant fluid properties, negligible conduction in the $\mathrm{x}$-direction and negligible viscous dissipation, the energy balance at any location in the fluid is given by Equation 2.

$$
\rho \mathrm{uC}_{\mathrm{p}} \frac{\partial \mathrm{T}}{\partial \mathrm{x}}=\mathrm{k} \frac{\partial^{2} \mathrm{~T}}{\partial \mathrm{y}^{2}} \quad ; \quad \mathrm{u}=\frac{3}{2} \mathrm{u}_{\mathrm{m}}\left(1-\left(\frac{2 \mathrm{y}}{\mathrm{H}}\right)^{2}\right)
$$


Hatton and Turton [1] generated an analytical solution for the temperature field by applying separation of variables, reducing Equation 2 to a Sturm-Liouville system, the first eight eigenvalues of which were computed numerically. Hatton and Turton then used $\mathrm{T}(\mathrm{x}, \mathrm{y})$ to obtain series expressions for $\mathrm{q}_{1}, \mathrm{q}_{2}$ and $\mathrm{T}_{\mathrm{m}}$ - each in dimensionless form a function of the inverse Graetz number, $\mathrm{X}$, only. Equation 3 provides the definition of $\mathrm{X}$ in accordance with Hatton and Turton [1].

$$
\mathrm{X}=\frac{2 \mathrm{x}}{\mathrm{H}} \cdot \frac{1}{\operatorname{Re} \cdot \operatorname{Pr}} \quad ; \quad \operatorname{Re}=\frac{\rho \mathrm{u}_{\mathrm{m}}(2 \mathrm{H})}{\mathrm{k}} \quad, \quad \operatorname{Pr}=\frac{\mathrm{C}_{\mathrm{p}}}{\mathrm{k}}
$$

Hatton and Turton presented their results in terms of local Nusselt numbers, $\mathrm{Nu}_{1}$ and $\mathrm{Nu}_{2}$, based on wall heat flux and the difference between the wall temperature and the mean fluid temperature, as defined in Equation 4.

$$
\mathrm{q}_{\mathrm{i}}=\mathrm{Nu}_{\mathrm{i}} \frac{\mathrm{k}}{2 \mathrm{H}} \cdot\left(\mathrm{T}_{\mathrm{i}}-\mathrm{T}_{\mathrm{m}}\right) \quad \mathrm{i}=1,2
$$

In Figure 3, a plot of $\left\{\mathrm{Nu}_{\mathrm{i}}\right\}$ for $\left\{\mathrm{r}_{\mathrm{T}}\right\}=\{0,1,2,3\}$ is reproduced from Hatton and Turton [1]. Two significant observations can be made about Figure 3. First, even though $\mathrm{q}_{1}$ is both continuous and finite for all $\mathrm{X}>0, \mathrm{Nu}_{1}$ has an extra singularity if $\mathrm{r}_{\mathrm{T}}>1$. This extra singularity arises because the driving temperature difference used to define $\mathrm{Nu}_{\mathrm{i}}$ is based on $\mathrm{T}_{\mathrm{m}}$ (Equation 4). For example, when $\mathrm{T}_{0}<\mathrm{T}_{1}<\mathrm{T}_{2}$ (as shown in Figure 2) $\mathrm{Nu}_{1}$ becomes indefinite in the location where $\mathrm{T}_{\mathrm{m}}=\mathrm{T}_{1}$. Moreover, $\mathrm{Nu}_{1}$ changes sign through this singularity, which is non-physical; $\mathrm{q}_{1}$ does not change sign until the temperature gradient normal to the wall becomes zero, i.e. at a local adiabatic point where $\mathrm{Nu}_{1}=0$. As shown by Mitrovic et al. [2], the singularity point, where $\mathrm{T}_{\mathrm{m}}=\mathrm{T}_{1}$ (dotted curve in Figure 2), is distinct from the local adiabatic point (dashed curve). Nield [3] asserted that the singularities seen in Figure 3 reduce the utility of the results. To address this deficiency, Nield [3] proposed a Nusselt number based on $\left(\mathrm{q}_{1}+\mathrm{q}_{2}\right)$ and $\left(\mathrm{T}_{\mathrm{wm}}-\mathrm{T}_{\mathrm{m}}\right)$. The heat flux to the fluid, $\left(\mathrm{q}_{1}+\mathrm{q}_{2}\right)$, and the driving temperature difference, $\left(\mathrm{T}_{\mathrm{wm}}-\mathrm{T}_{\mathrm{m}}\right)$, both decay to zero as the flow becomes thermally developed, and the sense of each remains unchanged in the process. Accordingly, the extra singularity does not arise. 


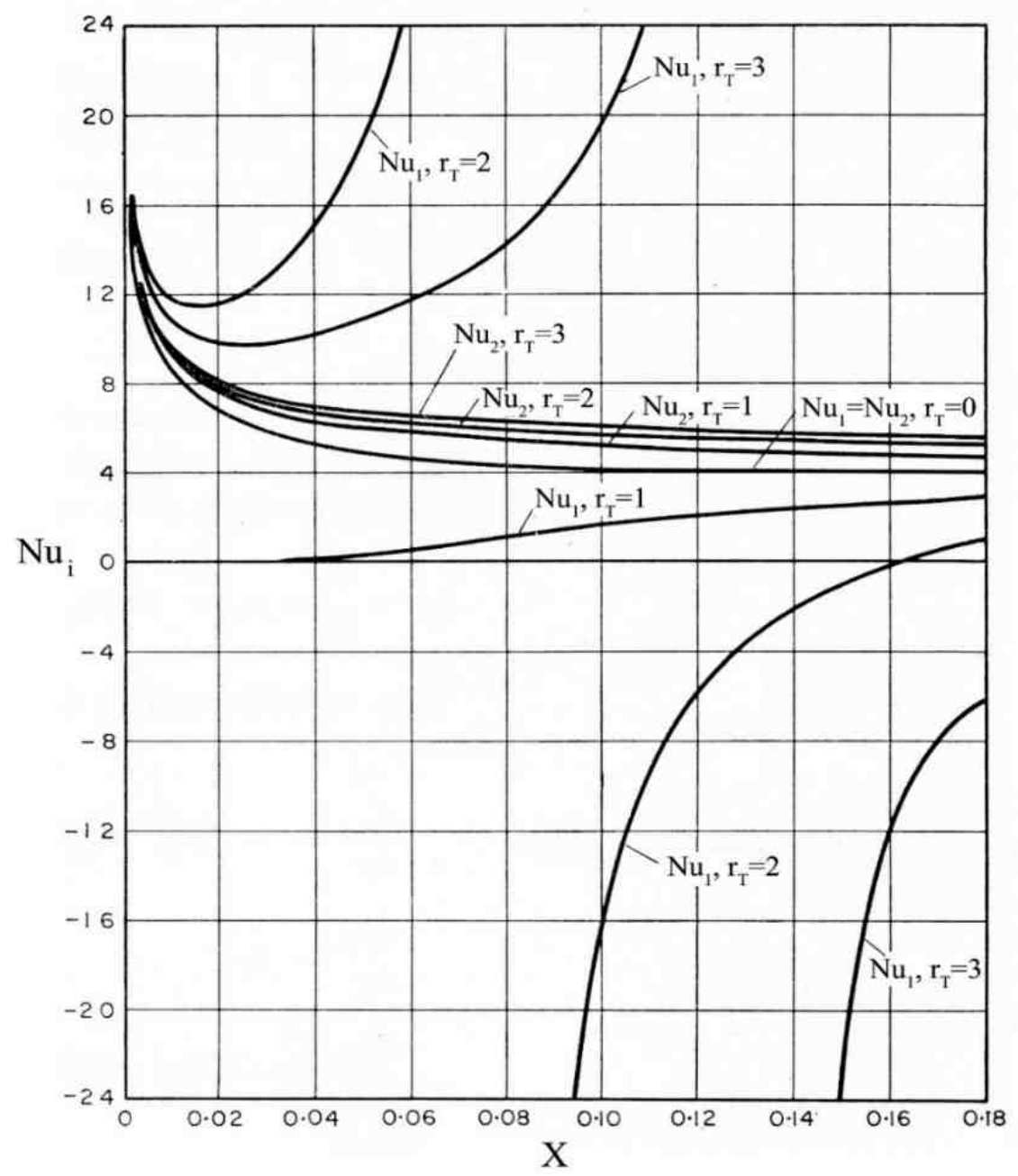

Figure 3 - Variation of local Nusselt numbers from the solution by Hatton and Turton [1] (reproduced with permission, labels altered to match current nomenclature)

The second, and more important, observation about the results of Hatton and Turton is that $\left\{\mathrm{Nu}_{\mathrm{i}}\right\}$ depends on $\mathrm{r}_{\mathrm{T}}$ which is unexpected. Recall that in the case of a two-temperature forcedconvection problem, e.g. flow in a symmetrically heated channel, the Nusselt number can be expressed as $\mathrm{Nu}=\mathrm{Nu}(\mathrm{Re}, \mathrm{Pr})$. Given that the only difference between the three-temperature and two-temperature cases is an additional non-homogenous (but linear) boundary condition, the nature of the solutions should be the same. In other words, it is expected that in the case of a three-temperature problem too, the solution could be expressed in terms of Nusselt number(s) that are independent of $r_{T}$. The results of Hatton and Turton exhibit this feature only in the thermally developed limit: $\lim _{\mathrm{X} \rightarrow \infty} \mathrm{Nu}_{1}=\lim _{\mathrm{X} \rightarrow \infty} \mathrm{Nu}_{2}=4$. Nield [3] showed that in the thermally fully 
developed limit, the modified Nusselt number based on $\left(\mathrm{q}_{1}+\mathrm{q}_{2}\right)$ and $\left(\mathrm{T}_{\mathrm{wm}}-\mathrm{T}_{\mathrm{m}}\right)$ is not influenced by asymmetry $\left(\mathrm{r}_{\mathrm{T}}\right)$. The dependence on $\mathrm{r}_{\mathrm{T}}$ has another problem: the solution cannot predict the limiting two-temperature case. According to Equation 1, $\mathrm{r}_{\mathrm{T}}$ becomes indefinite if $\mathrm{T}_{1}=\mathrm{T}_{2}$, causing another singularity in the solution. But as demonstrated by Nield [3], a properly defined Nusselt number would be identical for asymmetric and symmetric cases. Figure 3 might also lead to the conclusion that thermal development length of the flow is a function of $\mathrm{r}_{\mathrm{T}}$. This is not the case.

It should be mentioned that the motivation behind this work has been the desire to formulate steady-state heat transfer problems in terms of thermal-resistor networks. The resistor-network approach has significant computational advantages in the modeling of thermal phenomena, e.g. modeling heat transfer in windows for building energy simulation [4-6]. This paper demonstrates the formulation of a simple three-temperature convection problem in terms of a delta thermalresistor network and presents a method for calculating the individual convective resistances of the network. The asymmetric Graetz problem was chosen as an example three-temperature convection problem because due to the availability of an analytical solution. This work is part of an ongoing project on the modeling and characterization of multi-temperature convection problems encountered in building energy simulation in terms of resistor networks.

\section{THE RESISTOR-NETWORK FORMULATION OF THE PROBLEM}

Heat transfer rate at a wall from the channel entrance to any point, $\mathrm{Q}_{\mathrm{i}}$, is influenced by the three independent temperatures involved, i.e. the temperature boundary conditions $\left\{T_{i}\right\}$. More specifically, extending the traditional approach of formulating two-temperature heat transfer in terms of a driving temperature difference, a functional relation between $Q_{i}$ and the three temperature differences, $\left\{\mathrm{T}_{\mathrm{ij}}\right\}$, is postulated. See Equation 5 wherein $\mathrm{Q}_{\mathrm{i}}$ is expressed as a linearized summation with $\mathrm{T}_{\mathrm{ij}}$ explicitly factored out of each term. Any nonlinearity with respect to $\left\{\mathrm{T}_{\mathrm{i}}\right\}$ is contained in $\left\{\mathrm{C}_{\mathrm{ij}}\right\}$.

$$
Q_{i}=Q_{i}\left(\left\{\Delta T_{i j}\right\}\right)=\sum_{j} C_{i j}\left(T_{i}-T_{j}\right)
$$

The subscript ij is introduced to indicate that function $\mathrm{C}_{\mathrm{ij}}$ corresponds to the relation between a specific pair of temperatures: $T_{i}$ and $T_{j}$. Although it is anticipated, based on the two-temperature 
case, that $\mathrm{C}_{\mathrm{ij}}$ is constant for a given flow rate and constant fluid properties, no restriction on the form of $\mathrm{C}_{\mathrm{ij}}$ is assumed at this stage.

Equation 5 can be rewritten as Equation 6 where $C_{i j}$ is replaced by a new function: $R_{i j}=\frac{1}{C_{i j}}$.

$$
\mathrm{Q}_{\mathrm{i}}=\sum_{\mathrm{j}} \frac{\mathrm{T}_{\mathrm{i}}-\mathrm{T}_{\mathrm{j}}}{\mathrm{R}_{\mathrm{ij}}}
$$

Equation 6 now resembles energy balances at the nodes of a thermal network, such as the delta network shown in Figure 4. In Figure 4, each boundary temperature of the problem is represented by a temperature node - an isothermal heat source/sink. To represent the fluid flow, the inlet temperature, $\mathrm{T}_{0}$, is chosen because it is the independent temperature associated with the fluid, as opposed to, say, $\mathrm{T}_{\mathrm{m}}$ which is a function of all the boundary temperatures.

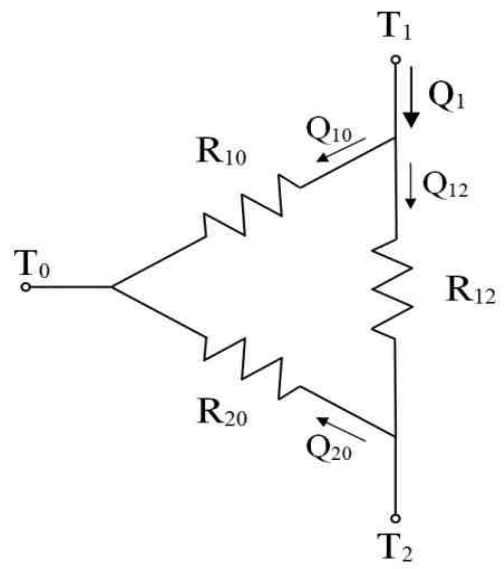

Figure 4 - Three-resistor thermal network of flow in asymmetrically heated channel

In connection to the thermal network of Figure 4, the functions $\mathrm{R}_{\mathrm{ij}}$ correspond to paired convective resistances that characterize the network. The term "paired" is used to emphasize that $\mathrm{R}_{\mathrm{ij}}$ corresponds to $\mathrm{Q}_{\mathrm{ij}}$, the heat transfer between a specific pair of nodes, $T_{i}$ and $T_{j}$. Heat transfer through each leg of the network can be written as shown in Equation 7.

\footnotetext{
* This choice of reference temperature is not unusual. In the study of heat exchangers, for instance, the same approach is taken to assess the performance of the device based on a maximum heat transfer potential (temperature difference).
} 


$$
\mathrm{Q}_{\mathrm{ij}}=\frac{\mathrm{T}_{\mathrm{i}}-\mathrm{T}_{\mathrm{j}}}{\mathrm{R}_{\mathrm{ij}}} \quad \mathrm{i}=0,1,2 \quad \mathrm{j}=0,1,2 \quad \mathrm{i} \neq \mathrm{j}
$$

Applying Equation 6 to the node representing the fluid ( $\mathrm{i}=0$ ), for example, the total heat transfer to the fluid will be given as the sum of two wall-to-fluid components. Similarly, heat transfer from a wall will be the sum of wall-to-fluid and wall-to-wall components.

If the set of convective resistances, $\left\{\mathrm{R}_{\mathrm{ij}}\right\}$, is known, heat transfer rate at the nodes, $\left\{\mathrm{Q}_{\mathrm{i}}\right\}$, can be calculated. Furthermore, the knowledge of $\left\{\mathrm{R}_{\mathrm{ij}}\right\}$ leads to a new insight: the split of heat transfer between the legs of the network, $\left\{\mathrm{Q}_{\mathrm{ij}}\right\}$, can now be resolved.

\section{EVALUATION OF THE PAIRED CONVECTIVE RESISTANCES}

To evaluate the set of paired resistances, $\left\{\mathrm{R}_{\mathrm{ij}}\right\}$, first Equation 6 is applied at node $\mathrm{T}_{1}$. In connection to the network of Figure 4, this means the total heat transfer at this node, $\mathrm{Q}_{1}$, is the sum of the heat transfer from $T_{1}$ to $T_{2}, Q_{12}$, and the heat transfer from $T_{1}$ to $T_{0}, Q_{10}$. See Equation 8.

$$
\mathrm{Q}_{1}=\frac{\mathrm{T}_{1}-\mathrm{T}_{2}}{\mathrm{R}_{12}}+\frac{\mathrm{T}_{1}-\mathrm{T}_{0}}{\mathrm{R}_{10}}=\mathrm{Q}_{12}+\mathrm{Q}_{10}
$$

A similar relation is written for $\mathrm{Q}_{2}$, as shown in Equation 9 .

$$
\mathrm{Q}_{2}=\frac{\mathrm{T}_{2}-\mathrm{T}_{1}}{\mathrm{R}_{12}}+\frac{\mathrm{T}_{2}-\mathrm{T}_{0}}{\mathrm{R}_{20}}
$$

Equation 6 also can be applied at $\mathrm{T}_{0}$. With $\left\{\mathrm{R}_{\mathrm{ij}}\right\}$ unknown, these nodal energy balances form a system of three equations and three unknowns. But these equations cannot be solved for the unknowns, $\left\{\mathrm{R}_{\mathrm{ij}}\right\}$, because they are not independent; they are interconnected through the overall energy balance of the network: $\mathrm{Q}_{0}+\mathrm{Q}_{1}+\mathrm{Q}_{2}=0$.

An observation about the functional dependence of convective resistances needs to be made at this point. For a given geometry, the convective resistances, $\left\{\mathrm{R}_{\mathrm{ij}}\right\}$, will be each a function of the velocity field and fluid properties. Any dependence on temperature will be caused by the effects of temperature on the velocity field, e.g. buoyancy, or temperature-dependent fluid properties. With the fluid properties assumed to be constant and the velocity profile known to be symmetric 
about $\mathrm{y}=0$, the two wall-to-fluid resistances must then be equal: $\mathrm{R}_{10}=\mathrm{R}_{20}$. This result is crucial in the solution presented here.

With $\mathrm{R}_{10}=\mathrm{R}_{20}$, Equations 8 and 9 can now be summed and rearranged to obtain Equation $10 .^{\dagger}$

$$
\mathrm{R}_{10}=\mathrm{R}_{20}=\frac{\mathrm{T}_{1}+\mathrm{T}_{2}-2 \mathrm{~T}_{0}}{\mathrm{Q}_{1}+\mathrm{Q}_{2}}=2 \frac{\left(\mathrm{T}_{\mathrm{wm}}-\mathrm{T}_{0}\right)}{\mathrm{Q}_{1}+\mathrm{Q}_{2}}
$$

Next, Equation 9 is subtracted from Equation 8 to obtain $R_{12}$. See Equation 11.

$$
\mathrm{R}_{12}=2\left[\left(\frac{\mathrm{Q}_{1}-\mathrm{Q}_{2}}{\mathrm{~T}_{1}-\mathrm{T}_{2}}\right)-\frac{1}{\mathrm{R}_{10}}\right]^{-1}=2\left[\frac{\mathrm{Q}_{1}-\mathrm{Q}_{2}}{\mathrm{~T}_{1}-\mathrm{T}_{2}}-\frac{\mathrm{Q}_{1}+\mathrm{Q}_{2}}{\mathrm{~T}_{1}+\mathrm{T}_{2}-2 \mathrm{~T}_{0}}\right]^{-1}
$$

Therefore, the resistances characterizing the thermal network of Figure 4 can be obtained for a set of imposed boundary temperatures if the heat transfer rates from the walls are known.

\section{PAIRED NUSSELT NUMBERS}

Hatton and Turton [1] obtained a series solution to Equation 2 in terms of the dimensionless temperature $\theta=\left(T-T_{w m}\right) /\left(T_{1}-T_{w m}\right)$, and in the form shown in Equation 12 .

$$
\theta=\left(\frac{2 y}{H}\right)-\sum_{n=1}^{\infty} C_{n} f_{n} \exp \left(-\frac{8}{3} \lambda_{n}^{2} X\right)
$$

In Equation 12, the first term on RHS is the linear, fully-developed temperature profile, and the summation is the series solution to a Sturm-Liouville system, with $C_{n}, f_{n}$ and $\lambda_{n}$ denoting the coefficients, the eigenfunctions and the eigenvalues, respectively. $\mathrm{X}$ is the inverse Graetz number, defined in Equation 3.

With the temperature distribution known, heat flux at either wall is obtained as shown in Equation 13, where $\bar{y}=2 y / H$ denotes dimensionless y-coordinate.

\footnotetext{
${ }^{\dagger}$ Note the difference between Equation 10 and the modified Nusselt number suggested by Nield [3]: instead of $\mathrm{T}_{\mathrm{m}}, \mathrm{T}_{0}$ is used as the fluid temperature. As discussed in Section IV, this difference turns out to be significant.
} 


$$
\begin{aligned}
\mathrm{q}_{\mathrm{i}} & =-\frac{\mathrm{k}}{\mathrm{H}}\left(\mathrm{T}_{1}-\mathrm{T}_{2}\right)\left(\frac{\partial \theta}{\partial \overline{\mathrm{y}}}\right)_{\overline{\mathrm{y}}_{\mathrm{i}}} \\
& =-\frac{\mathrm{k}}{\mathrm{H}}\left(\mathrm{T}_{1}-\mathrm{T}_{2}\right)\left[1-\sum_{\mathrm{n}=1}^{\infty} \mathrm{C}_{\mathrm{n}}\left(\frac{\mathrm{df}}{\mathrm{d} \overline{\mathrm{y}}}\right)_{\overline{\mathrm{y}}_{\mathrm{i}}} \exp \left(-\frac{8}{3} \lambda_{\mathrm{n}}^{2} \mathrm{X}\right)\right]
\end{aligned}
$$

Heat fluxes are then integrated from the channel entrance to any location $\mathrm{x}$, to find the total heat transfer rates, $\mathrm{Q}_{1}$ and $\mathrm{Q}_{2}$. See Equation 14 .

$$
\begin{aligned}
Q_{i} & =\int_{0}^{x} q_{i} d x \\
& =-\frac{k}{H}\left(T_{1}-T_{2}\right) \int_{0}^{x}\left[1-\sum_{n=1}^{\infty} C_{n}\left(\frac{d f_{n}}{d \bar{y}}\right)_{\bar{y}_{i}} \exp \left(-\frac{8}{3} \lambda_{n}^{2} X\right)\right] d x
\end{aligned}
$$

The summation can be integrated as shown in Equation 15.

$$
\begin{aligned}
\int\left[\sum_{n=1}^{\infty} C_{n}\left(\frac{d f_{n}}{d \bar{y}}\right)_{y_{i}} \exp \left(-\frac{8}{3} \lambda_{n}^{2} X\right) d x\right. \\
=\operatorname{Re} \cdot \operatorname{Pr}\left(\frac{H}{2}\right) \sum_{n=1}^{\infty}\left\{C_{n}\left(\frac{d f_{n}}{d \bar{y}}\right) \int \exp \left(-\frac{8}{3} \lambda_{n}^{2} X\right) d X\right\} \\
=\operatorname{Re} \cdot \operatorname{Pr}\left(\frac{H}{2}\right) \sum_{n=1}^{\infty}\left\{-\frac{3 C_{n}}{8 \lambda_{n}^{2}}\left(\frac{d f_{n}}{d \bar{y}}\right) \exp \left(-\frac{8}{3} \lambda_{n}^{2} X\right)\right\}
\end{aligned}
$$

Finally, Equations 10 and 11 are used to obtain $\left\{\mathrm{R}_{\mathrm{ij}}\right\}$. To report the results in dimensionless form, average paired Nusselt numbers, $\left\{\overline{\mathrm{Nu}_{\mathrm{ij}}}\right\}$, are defined as shown in Equation 16.

$$
\mathrm{Q}_{\mathrm{ij}}=\frac{\left(\mathrm{T}_{\mathrm{i}}-\mathrm{T}_{\mathrm{j}}\right)}{\mathrm{R}_{\mathrm{ij}}}=\overline{\mathrm{Nu}_{\mathrm{ij}}} \frac{\mathrm{k}}{\mathrm{H}} \times\left(\mathrm{T}_{\mathrm{i}}-\mathrm{T}_{\mathrm{j}}\right) \quad \mathrm{i}=1,2 \quad \mathrm{j}=0,1,2 \mathrm{i} \neq \mathrm{j}
$$


Equations 17 and 18 are the expressions obtained for $\left\{\overline{\mathrm{Nu}_{\mathrm{ij}}}\right\}$, using the eigenvalues and eigenfunctions reported by Hatton and Turton [1]. *

$$
\begin{aligned}
& \overline{\mathrm{Nu}_{12}}=\frac{1}{\mathrm{X}}\left(\mathrm{X}-0.2+0.2276 \mathrm{e}^{-7.54 \mathrm{X}}\right. \\
& -0.0367 \mathrm{e}^{-35.96 \mathrm{X}}-0.0133 \mathrm{e}^{-85.73 \mathrm{X}}-0.0066 \mathrm{e}^{-156.83 \mathrm{X}} \\
& +0.0038 \mathrm{e}^{-249.27 \mathrm{X}}-0.0025 \mathrm{e}^{-363.04 \mathrm{X}}+0.0017 \mathrm{e}^{-498.15 \mathrm{X}} \\
& -0.0012 \mathrm{e}^{-654.59 \mathrm{X}}+0.0009 \mathrm{e}^{-832.39 \mathrm{X}}-0.0001 \mathrm{e}^{-1031.47 \mathrm{X}} \\
& +0.0006 \mathrm{e}^{-1251.93 \mathrm{X}}-0.0005 \mathrm{e}^{-1493.69 \mathrm{X}}+0.0004 \mathrm{e}^{-1756.80 \mathrm{X}} \\
& \left.-0.0003 \mathrm{e}^{-2041.25 \mathrm{X}}+0.0003 \mathrm{e}^{-2347.03 \mathrm{X}}-0.0002 \mathrm{e}^{-2674.81 \mathrm{X}}\right) \\
& \overline{\mathrm{Nu}_{10}}=\overline{\mathrm{Nu}_{20}}=\frac{1}{\mathrm{X}}\left(0.5-0.4552 \mathrm{e}^{-7.54 \mathrm{X}}-0.0266 \mathrm{e}^{-85.73 \mathrm{X}}\right. \\
& -0.0076 \mathrm{e}^{-249.27 \mathrm{X}}-0.0034 \mathrm{e}^{-498.15 \mathrm{X}}-0.0019 \mathrm{e}^{-832.39 \mathrm{X}} \\
& \left.-0.0012 \mathrm{e}^{-1251.93 \mathrm{X}}-0.0008 \mathrm{e}^{-1756.80 \mathrm{x}}-0.0006 \mathrm{e}^{-2347.03 \mathrm{X}}\right)
\end{aligned}
$$

As expected, no dependence on $\left\{T_{i}\right\}$ or $r_{T}$ is observed. The paired Nusselt numbers depend only on $\mathrm{X}$, i.e. a combination of geometry, flow rate and fluid properties. The obtained $\left\{\overline{\mathrm{Nu}_{\mathrm{ij}}}\right\}$ can be used for any $\left\{T_{i}\right\}$, including the two-temperature case. In Figure 5, the above expressions for $\overline{\mathrm{Nu}_{10}}$ and $\overline{\mathrm{Nu}_{12}}$ as well as approximations obtained by keeping the first exponential terms only are

plotted versus $\mathrm{X}$. It can be seen that the first-exponent approximation to $\overline{\mathrm{Nu}_{12}}$ shows significant deviation from Equation 17 for $X \lesssim 0.1$, but very close agreement for $X>0.1$. The one-exponent approximation to $\overline{\mathrm{Nu}_{10}}$ replicates Equation 18 for essentially all $\mathrm{X}>0$.

\section{LOCAL PAIRED NUSSELT NUMBERS}

To make direct comparison with the local Nusselt numbers reported by Hatton and Turton (Figure 3) possible, a local paired Nusselt number, $\mathrm{Nu}_{\mathrm{ij}}$, may also be defined based on wall heat flux at location $x$ such that $\mathrm{Nu}_{\mathrm{ij}}$ corresponds to $\mathrm{q}_{\mathrm{ij}}$, the component of $\mathrm{q}_{\mathrm{i}}$ driven by $\left(\mathrm{T}_{\mathrm{i}}-\mathrm{T}_{\mathrm{j}}\right)$. Equation 19 provides the definition.

\footnotetext{
$\mp$ Noting that $\mathrm{q}_{\mathrm{i}}$ has an integrable singularity at $\mathrm{X}=0$, the lower limit of the integral of Equation 14 was adjusted to $10^{-4}$.
} 


$$
\mathrm{q}_{\mathrm{ij}}=\mathrm{Nu}_{\mathrm{ij}} \frac{\mathrm{k}}{\mathrm{H}}\left(\mathrm{T}_{\mathrm{i}}-\mathrm{T}_{\mathrm{j}}\right) \quad \mathrm{i}=1,2 \quad \mathrm{j}=0,1,2 \quad \mathrm{i} \neq \mathrm{j}
$$

The heat flux, $\mathrm{q}_{\mathrm{ij}}$, can be evaluated using Equation 20 .

$$
\mathrm{q}_{\mathrm{ij}}=\frac{\partial \mathrm{Q}_{\mathrm{ij}}}{\partial \mathrm{x}}=\frac{\mathrm{k}}{\mathrm{H}}\left(\mathrm{T}_{\mathrm{i}}-\mathrm{T}_{\mathrm{j}}\right) \frac{\mathrm{d}}{\mathrm{dx}}\left(\overline{\mathrm{Nu}_{\mathrm{ij}} \mathrm{x}}\right)
$$

Combining Equations 19 and 20, a relation between the local and average paired Nusselt numbers is obtained. See Equation 21.

$$
\mathrm{Nu}_{\mathrm{ij}}=\frac{\mathrm{d}}{\mathrm{dX}}\left(\overline{\mathrm{Nu}_{\mathrm{ij}}} \mathrm{X}\right)
$$

The local paired Nusselt numbers are plotted in Figure 6. The temperature profiles of Figure 2 may be used to gain insight into these results. Near the inlet there is a core at $T_{0}$ which is not affected by heat transfer from the walls. Downstream where the boundary layers merge, this core vanishes and the temperature profile eventually evolves into a linear profile which is independent of the inlet conditions. Accordingly, $\mathrm{Nu}_{10}$ starts from infinity at the inlet similar to forced convection over a flat plate. Moving downstream wall-to-fluid heat transfer decays to zero in the thermally-developed limit. Accordingly, $\mathrm{Nu}_{10} \approx 0$ for $\mathrm{X} \gtrsim 0.7$. The variation of $\mathrm{Nu}_{12}$ along the channel follows a different trend: at the entrance region, where there is enhanced heat transfer between the walls and the fluid, the walls do not "communicate" thermally; $\mathrm{Nu}_{12} \approx 0$ for $0 \leq \mathrm{X} \lesssim 0.05$. For $\mathrm{X}>0.05$, as the two thermal boundary layers become thicker, $\mathrm{Nu}_{12}$ increases, approaching the pure-condition limit of $\mathrm{Nu}_{12}=1$.

The two curves shown in Figure 6 can be used to replace the entire family of $r_{T}$-dependent curves shown in Figure 3. In comparison with Figure 3, the curves of Figure 6 are also a better presentation of the thermal development of the flow. It can be seen that the thermal development length is a function of $X$ only; regardless of $r_{T}$, the flow reaches thermal development essentially by $\mathrm{X} \approx 0.7$. 


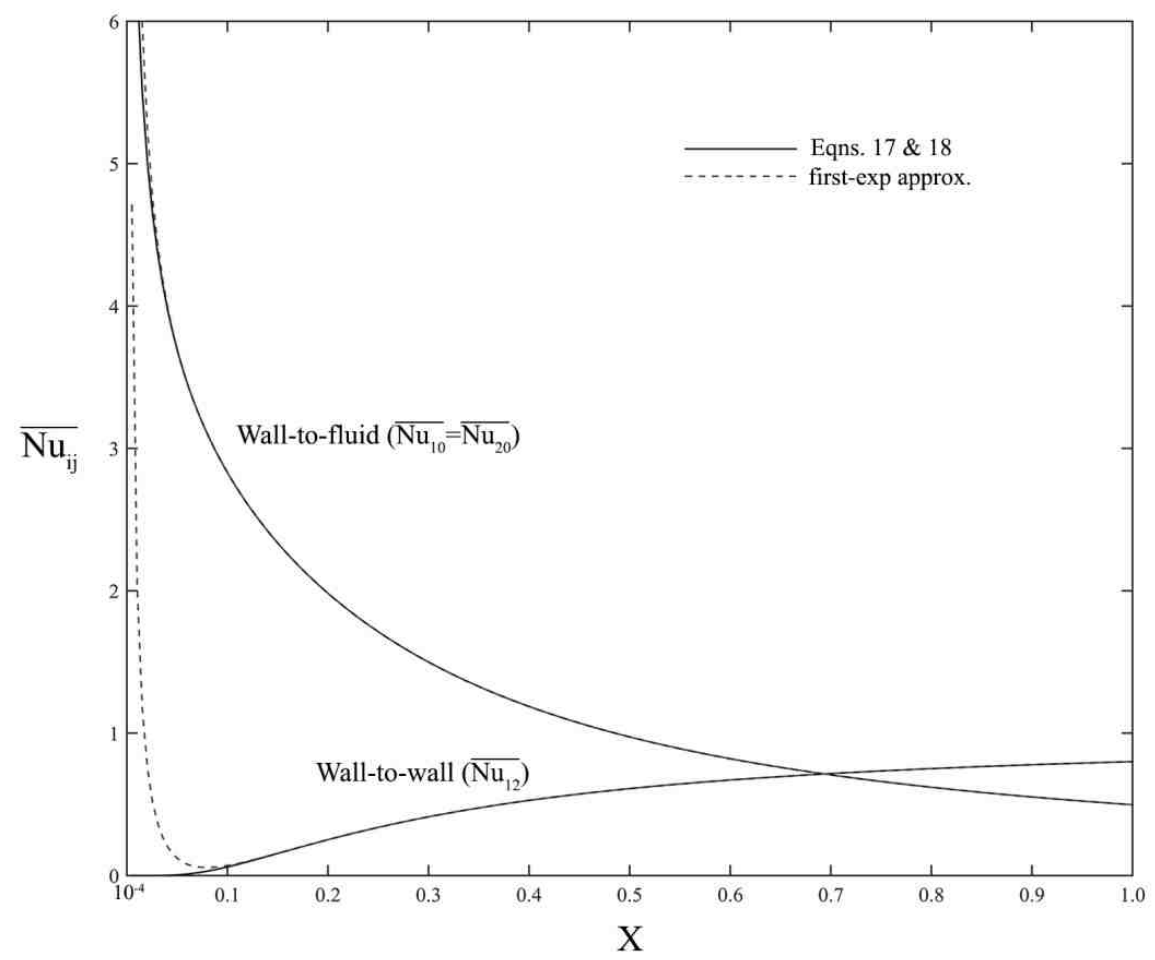

Figure 5 - Distribution of average paired Nusselt Numbers $\left(\overline{\mathrm{Nu}_{\mathrm{ij}}}\right)$

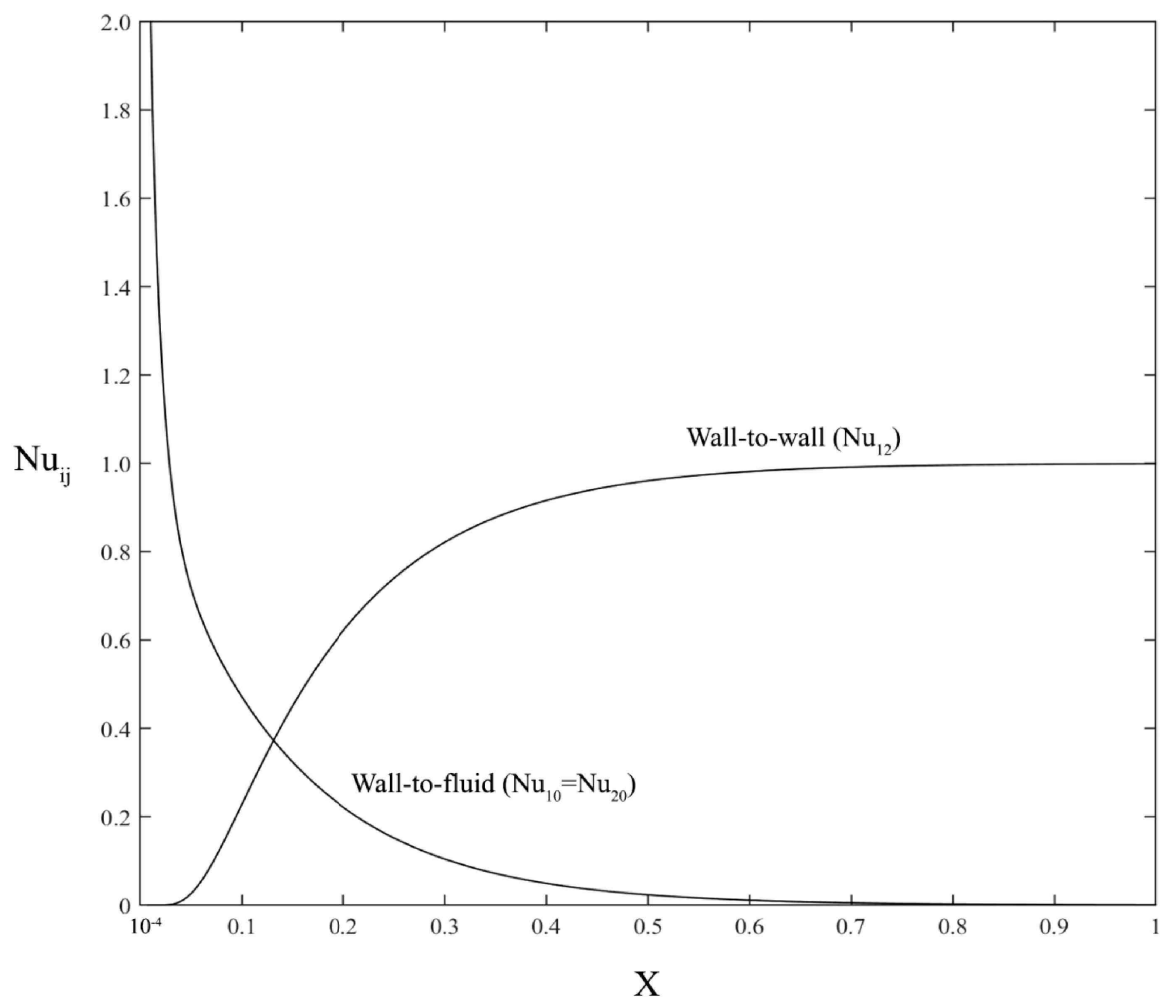

Figure 6 - Distribution of local paired Nusselt Numbers $\left(\mathrm{Nu}_{\mathrm{ij}}\right)$ 
In summary, the characterization of this three-temperature convection problem in terms of a delta thermal-resistor network leads to several advantages:

- A more complete picture emerges; the split of heat transfer between the different temperature nodes can now be resolved using the paired Nusselt numbers.

- The extra singularities observed in Figure 3 are eliminated.

- The trends are more consistent with the physics of the problem: the wall-to-wall Nusselt numbers start from zero at the entrance and approach the pure-conduction limit as $X \rightarrow \infty$, while the wall-to-fluid Nusselt number starts from infinity at the inlet and smoothly decays to zero in the thermally development limit.

- The paired Nusselt numbers are independent of temperature ratio (and temperature).

- With Reynolds and Prandtl numbers incorporated in the Graetz number, two universal Nusselt-number distributions are obtained that can be applied to any fluid, any laminar flow rate and any temperature ratio.

\section{CONCLUSION}

The classical problem of heat transfer to laminar hydrodynamically-developed flow through an asymmetrically heated channel, the asymmetric Graetz problem, was investigated in a resistornetwork framework. It was shown that the problem can be represented by a delta network entailing three thermal resistors. Due to symmetry, the two wall-to-fluid resistances are equal, reducing the number of the unknowns to two and making the system of equations resulting from nodal energy balances solvable. Using a previous analysis from the literature, analytical expressions were obtained for the wall-to-wall and wall-to-fluid resistances. Formulating this problem in terms of a thermal-resistor network has several advantages. Notably, the singularities observed in a previous solution have been eliminated, and Nusselt numbers were obtained which are independent of temperature ratio. Moreover, the split of heat transfer between different temperature nodes can now be resolved using the proposed paired Nusselt numbers.

In the development of a thermal-resistor network for this problem, no assumptions were made regarding the nature of the flow. This resistor-network approach, which provides a compact presentation of the results, is hence applicable even if the flow is hydrodynamically developing; if the fluid properties are not constant; or if the flow is turbulent. The evaluation of the resistances will however be more complicated. The more general case where symmetry cannot 
be invoked, i.e. when the two wall-to-fluid resistances are not equal, as well as the extension of the resistor-network approach to the generic problem of multi-temperature convection will be presented in future works. In extending the methodology, the analytical results presented in this paper will be used to validate a generic technique for evaluating paired resistances of complex multi-temperature convection problems.

\section{REFERENCES}

[1] Hatton, A.P., and Turton, J.S.., "Heat Transfer in The Thermal Entry Length with Laminar

Flow Between Parallel Walls at Unequal Temperatures," Intl. J. Heat Mass Transfer, Vol. 5, No.7, 1962, pp. 673, 679.

[2] Mitrović, J., Maletić. B., and Bačlić, B.S., "Some Peculiarities of the Asymmetric Graetz Problem,” Intl. J. Eng. Science, Vol. 44, No. 7, 2006, pp. 436, 455.

doi: 10.1016/j.ijengsci.2006.02.003

[3] Nield, D.A., "Forced Convection in a Parallel Plate Channel with Asymmetric Heating," Intl. J. Heat Mass Transfer, Vo. 47, No. 25, 2004, pp. 5609, 5612.

doi: 10.1016/j.ijheatmasstransfer.2004.07.006

[4] Wright, J.L., Barnaby, C.S., Niles, P., and Rogalsky, C.J., "Efficient Simulation of Complex Fenestration Systems in Heat Balance Room Models," 12th International Conference of the International Building Performance Simulation Association, Sydney, Australia, 2011, pp. 2851, 2858.

[5] Barnaby, C.S., Wright, J.L., and Collins, M.R., "Improving Load Calculations for Fenestration with Shading Devices," ASHRAE Transactions, Vol. 115, Part 2, 2009, pp. 31, 44.

[6] Foroushani, S.S.M., Wright, J.L., Naylor, D., and Collins, M.R., “Assessing Convective Heat Transfer Coefficients Associated with Indoor Shading Attachments Using a New Technique Based on Computational Fluid Dynamics,” ASHRAE Winter Conference, Chicago, Il, 2015. 